\title{
The effect of endotoxin and anti-endotoxin serum on synovial fluid parameters in the horse
}

\author{
R D Gottschalk ${ }^{a}, F$ Reyers ${ }^{b}$ and S S van den Berg ${ }^{a}$
}

\begin{abstract}
The effects of a commercially available equine hyperimmune anti-endotoxin serum on synovial fluid parameters were evaluated in an induced synovitis model in normal horses. Four groups of 3 horses each received lipopolysaccharide (LPS) plus hyperimmune antiendotoxin (anti-LPS), LPS, anti-LPS, and Ringers lactate (control) respectively injected into the left intercarpal joint. Synovial fluid parameters were measured at 4, 8, 24 and $72 \mathrm{~h}$. It was found that anti-LPS had no attenuating effect on the LPS and that it induced a synovitis almost equivalent to that induced by LPS alone. The introduction of sterile Ringers lactate solution into the carpal joint together with repeated aseptic arthrocentesis induces a mild inflammatory response.
\end{abstract}

Key words: endotoxin, horses, hyperimmune anti-endotoxin, synovitis.

Gottschalk R D, Reyers F, Van den Berg S S The effect of endotoxin and anti-endotoxin serum on synovial fluid parameters in the horse. Journal of the South African Veterinary Association (1998) 69(1): 7-11 (En.). Department of Surgery, Faculty of Veterinary Science, Private Bag X04, Onderstepoort, 0110 South Africa.

\section{INTRODUCTION}

Septic arthritis in horses of all ages remains a difficult therapeutic challenge. Despite early diagnosis and appropriate vigorous therapy, the prognosis for return to athletic function is gaurded ${ }^{1}$. The trend appears to be towards increased aggressiveness in the treatment of septic arthritis ${ }^{6,23}$. As this frustrating disease often defies treatment, veterinarians may resort to ill-defined therapeutic methods in the hope of achieving a better response.

Literature on the use of equine hyperimmune anti-endotoxin (anti-LPS) serum in the treatment of septic arthritis in horses is based on reports of its use in clinical cases $^{27}$. Anti-LPS plasma has also been used for the treatment of gastroenteritis and endotoxaemia in horses ${ }^{8}$, in cases of haemorrhagic enteric endotoxaemia in $\operatorname{dogs}^{31,32}$ and Pseudomonas keratitis in rabbits ${ }^{30}$. However, the conclusions based on clinical studies may be confounded by various factors, including the bacterial agent involved, the method and dose of inoculation, the duration of

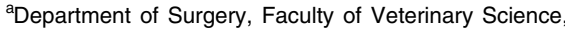
University of Pretoria, Private Bag X04, Onderstepoort, 0110 South Africa.

${ }^{b}$ Department of Medicine, Faculty of Veterinary Science, University of Pretoria, Private Bag X04, Onderstepoort, 0110 South Africa.

Received: August 1996. Accepted: November 1997. infection, host immunological defence competence, concurrent systemic disease, pre-existing joint pathology and the treatment protocol employed ${ }^{22}$.

The main purpose of this study was to evaluate the use of a commercially available equine hyperimmune antiendotoxin preparation ${ }^{27}$ in an induced synovitis model $^{7}$, as well as to define its effects in normal equine joints.

\section{MATERIALS AND METHODS}

\section{Subjects}

Twelve clinically normal horses (8 mares, a stallion and 3 geldings), ranging in age from 3-18 years, with a mass ranging from $320-505 \mathrm{~kg}$ (average $407 \mathrm{~kg}$ ) were used in the study. The predominant breed was Thoroughbred with 1 American saddle horse and 3 horses of mixed breed. The animals were stabled and Eragrostis teff and Medicago sativa hay as well as water were available ad libitum. Clean and plentiful wheaten straw was used for bedding.

\section{Experimental design}

The 12 horses were randomly allocated to 1 of 4 groups. The treatment groups, each comprising 3 horses, were:

Group I: lipopolysaccharide (LPS) and anti-LPS treatments. LPS was injected into the left intercarpal joint of the horses at a dosage rate of $0.1 \mu \mathrm{g} / \mathrm{kg}$ body weight ${ }^{7}$.
The dose was reconstituted in $5 \mathrm{~m} \ell$ of sterile Ringers lactate (Ringer-Lactate, Sabax). Immediately after injection of LPS, $5 \mathrm{~m} \ell$ equine anti-endotoxin hyperimmune serum was injected through the same needle used to inject the LPS.

Group II: treatment with LPS alone. A dose of $0.1 \mu \mathrm{g}$ LPS $/ \mathrm{kg}$ body mass, reconstituted in $5 \mathrm{~m} l$ Ringers lactate (as above), was injected into the left intercarpal joint of each horse in this group.

Group III: treatment with anti-LPS alone. Five $\mathrm{m} \ell$ anti-LPS was injected into the left intercarpal joint of each horse.

Group IV: Ringers lactate control group. Five $\mathrm{m} \ell$ Ringers lactate ( $\mathrm{pH}$ 6.5) was injected into the left intercarpal joint of each horse.

The source of the LPS (E. coli, 055:B5, lot 17F4019, Sigma Chemical Corporation, USA) was a freeze-dried lipopolysaccharide preparation derived from Escherichia coli, serotype 055:B5. The antiLPS used was a commercial preparation of equine anti-endotoxin hyperimmune serum, Atoxin ${ }^{\circledR}$ (Atoxin, Atox Pharmaceutical Company) containing $1200 \mu \mathrm{g} / \mathrm{m} l$ anti-LPS precipitable IgG obtained by plasmapheresis of suitably immunised healthy horses ${ }^{9}$. The anti-LPS has an affinity for LPS prepared from Escherichia coli 055:B5, as well as Salmonella typhimurium, S. typhi, S. abortus equi, Shigella flexneri, E. coli 0127:B8 and S. enteritides ${ }^{28}$.

\section{Duration}

The duration of the experimental procedure in each animal was $72 \mathrm{~h}$. Synovial fluid was collected before injection of substances and repeated 6 times (vide infra).

\section{Experimental procedure}

During the 72-h experimental period all the horses were stabled. Clinical evaluations were performed in the stable, with the exception of lameness assessments, for which the horses were walked and trotted on a grass lawn adjacent to the stables. Horses that were unwilling to take full weight on the affected leg were evaluated in the stable only. 
Most of the horses tolerated the arthrocentesis procedure without resistance. In the isolated cases where the horses were fractious and/or resisted the procedure, a twitch, applied to the upper lip, was used for restraint.

\section{Intra-articular injection of substances and synovial fluid collection}

On the day preceding the trial the skin over the left carpus of each horse was prepared by shaving, thorough scrubbing for at least 2 min with chlorhexidine disinfectant soap (Hibiscrub, chlorhexidine gluconate $4 \mathrm{~g} / 100 \mathrm{~m}$, ICI Pharmaceuticals, Woodmead) and sprayed with a $1 \%$ Povidone iodine solution (Adcock Ingram Laboratories, Johannesburg). The substances were injected using a strictly aseptic technique into the left intercarpal joint of each horse at time $0 \mathrm{~h}$.

Immediately before intra-articular injection or arthrocentesis, the skin over the carpal joints was again scrubbed with chlorhexidine and sprayed with $1 \%$ povidone iodine. The povidone iodine was removed by swabbing with clean cotton wool, starting at the proposed site of injection (or synovial fluid collection) and working outwards. The povidone iodine spraying procedure was repeated 3 times, and the last application was not swabbed off. Strictly aseptic technique was observed by scrubbing hands with a chlorhexidine surgical scrub and gloving with disposable sterile latex surgical gloves.

After skin preparation, a $0.7 \mathrm{~mm}$ diameter by $38 \mathrm{~mm}$ long sterile hypodermic needle (Terumo single-use needle, Terumo Corporation, Tokyo, Japan) was introduced into the intercarpal joint between the tendon of the $M$. extensor carpi radialis and the $M$. extensor digitorum muscles. The correct placement of the needle was confirmed by the presence of synovial fluid in the hub of the needle. The syringe was attached to the hub of the needle only after correct placement was ascertained. A $5 \mathrm{ml}$ syringe was used to inject the specific substance or to draw off approximately $3 \mathrm{ml}$ of synovial fluid for analysis.

When synovial fluid was collected it was immediately transferred to a $5 \mathrm{~m} \iota$ capacity, evacuated tube (B D Vacutainer, Becton Dickenson Co., USA) containing $57 \mu \ell$ of a $15 \%$ solution of tri-potassium ethylene diamine tetra-acetic acid (EDTA). The tube was agitated to ensure even distribution of EDTA in the synovial fluid sample. Samples for synovial fluid analysis were delivered to the laboratory within $30 \mathrm{~min}$ of collection and processed within $60 \mathrm{~min}$

\section{Bacterial sampling}

To ensure that no bacterial infection was introduced into the joints, and that all effects seen could be attributed to the substances used, bacteriological examinations were conducted on the LPS and anti-LPS solutions before their introduction into the joints, as well as on synovial fluid collected at $72 \mathrm{~h}$.

The synovial fluid samples were collected aseptically and transferred into blood culture bottles (Oxoid Signal Blood Culture Medium, BC102, Oxoid Limited). These samples were delivered to the laboratory within $20 \mathrm{~min}$ of collection.

\section{Laboratory data}

Synovial fluid was collected at 0, 2, 4, 8, $24,32,48$ and $72 \mathrm{~h}$. Analysis of the fluid was performed by an experienced technologist in the section of Clinical Pathology, Faculty of Veterinary Science, University of Pretoria. Total synovial fluid protein was determined using the biuret reaction on an automated chemical analyser (Technicon Instruments Corporation). A nucleated cell count (NCC) was conducted on a 1:1000 dilution treated with Zappoglobin (Coulter Electronics), to lyse the erythrocytes, on a Coulter model Fn (Coulter Electronics). A differential count was performed to determine the number of each cell type present on a thin smear of synovial fluid stained with CAMS Quick Stain (C A Milsch). The number of each cell type encountered during the classification of 100 nucleated cells was counted and multiplied by the $\mathrm{NCC}^{4}$.

\section{Clinical data}

Rectal temperature and heart rate were recorded every hour for the 1 st $24 \mathrm{~h}$ and thereafter every $6 \mathrm{~h}$.

\section{Clinical observations}

These were made every $6 \mathrm{~h}$ for the 1 st $24 \mathrm{~h}$ and thereafter every $12 \mathrm{~h}$. Lameness was evaluated according to a system modified from Stashak ${ }^{25}$ and graded from Grade 0 (no lameness) to Grade IV (nonweight-bearing lameness). Discomfort at rest in the stall was graded from Grade 0 (no obvious discomfort) to Grade IV (recumbent, or sweating with colic-like symptoms). Pain on palpation and flexion of the joint was graded from Grade 0 (no pain on digital palpation of the carpal joint, no resistance to flexion) to Grade III where digital palpation was not tolerated and flexion of the joint was resisted. All these subjective clinical observations were made by the same person.

\section{Statistical analysis}

For all analyses, the SAS program for analysis of general linear models, univariate and multivariate analysis of variance (MANOVA) (SAS Institute) was used. Wilks' criterion was computed using the MANOVA test for the hypothesis of no overall group effect. F-tests were conducted to test the hypothesis of no group differences in the case of univariate analysis.

Pearson's correlation coefficients were computed amongst the synovial fluid parameters at specific times of collection.

As a measure of comparison of the 4 groups in the experiment, the least square means were computed. Since multiple comparisons between groups were carried out, the Bonferroni inequality was calculated to provide an overall probability of error smaller than usually demanded. This was achieced by multiplying the least square means probabilities by a factor of 6 because pairwise comparisons were made ${ }^{18}$. This test was performed on all parameters at 4, 8,24 and $72 \mathrm{~h}$, as these were considered to be the times that would indicate the differences between the groups most effectively. The level of significance for all tests was set at $p<0.05$.

The clinical parameters, although statistically analysed, are not reported in this paper as they were subjective in nature and the treatment groups were relatively small. Their relationship to the synovial fluid findings, however, is alluded to in the discussion.

The number of horses allocated per treatment group was based on the formula by Steel \& Torrie ${ }^{26}$, the variance recorded in data published by Firth ${ }^{7}$ and literature on equine synovial protein and neutrophil changes in septic arthritis ${ }^{12,15}$.

The protocol was approved by the institutional Ethics and Research Committees. A clause was included allowing for the treatment or euthanasia of animals showing excessive pain during the trial. Animals showing any signs of pain or discomfort at the end of the trial were treated appropriately.

\section{RESULTS}

\section{Synovial fluid total protein}

The protein values peaked dramatically, from a mean base line of $14.9 \mathrm{~g} / \mathrm{l}$, in Groups I, II and III at $12 \mathrm{~h}$, after which they gradually decreased (Fig. 1). At $72 \mathrm{~h}$ the mean values were still substantially higher than baseline values. The mean values of $67 \mathrm{~g} / \mathrm{l}$ in Group I and $66.7 \mathrm{~g} / \mathrm{l}$ in Group II at $8 \mathrm{~h}$ are as high as the total serum protein values of $65.85 \pm 6.64 \mathrm{~g} / \mathrm{l}$ in 
normal horse blood ${ }^{16}$. The highest recorded mean total synovial fluid protein values in Groups III and IV were $51.8 \mathrm{~g} / \mathrm{l}$ and $38 \mathrm{~g} / \mathrm{l}$ at 12 and $24 \mathrm{~h}$ respectively.

Statistically, the overall group mean total synovial total protein values differed significantly (Wilks' criterion $p=0.0183$ ). Using the Bonferroni test, there was no difference between the mean values of Groups I, II and III at any time during the trial. Group IV (control) was markedly different from all other groups at all time intervals after time $=0 \mathrm{~h}$.

\section{Nucleated cell count (NCC)}

This parameter showed dramatic, statistically significant, increases in Groups I and II (Fig. 2). Eight hours post-injection the mean value of NCC in these groups had increased 325 times their baseline values. The Bonferroni test showed no differences between these 2 groups at any time during the trial period. The anti-LPS group (Group III) also demonstrated a marked increase in the first $8 \mathrm{~h}$, but not to the same extent as Groups I and II, with a mean increase of 178 times baseline values. There was no significant difference between Group III and Groups I and II. Group IV (control) increased to a mean of 40 times the baseline value. However, this was significantly less than the other Groups during the 3-12 h post-injection period. A high correlation was found between NCC and synovial fluid protein at 4 and $8 \mathrm{~h}(r=0.9321$ and 0.9668 respectively).

\section{Neutrophil count}

Neutrophils were the predominant cell type observed in the joint effusion of all groups. Mean values of 152000 cells $/ \mu \ell$ were found in Group I and 154000 cells/ $\mu l$ in Group II at $12 \mathrm{~h}$ (Fig. 3). These values dropped almost as dramatically as they rose to means of 19900 and 13500 cells/ $\mu l$ respectively at $72 \mathrm{~h}$. Group III reached a lower peak than Groups I and II at a mean value of 90000 cells $/ \mu l$ at $12 \mathrm{~h}$. There was, however, no significant difference between Groups I, II and III, while Group IV values were significantly lower, than these groups throughout the trial after time $=0 \mathrm{~h}$

\section{DISCUSSION}

The significant increase in protein values (Fig. 1) in the joint fluid can be attributed to increased vascular permeability ${ }^{3}$, which may result from damage to arterioles, venules and capillaries inflicted by the agents injected into the joints, or indirectly from the stimulus of released chemical mediators

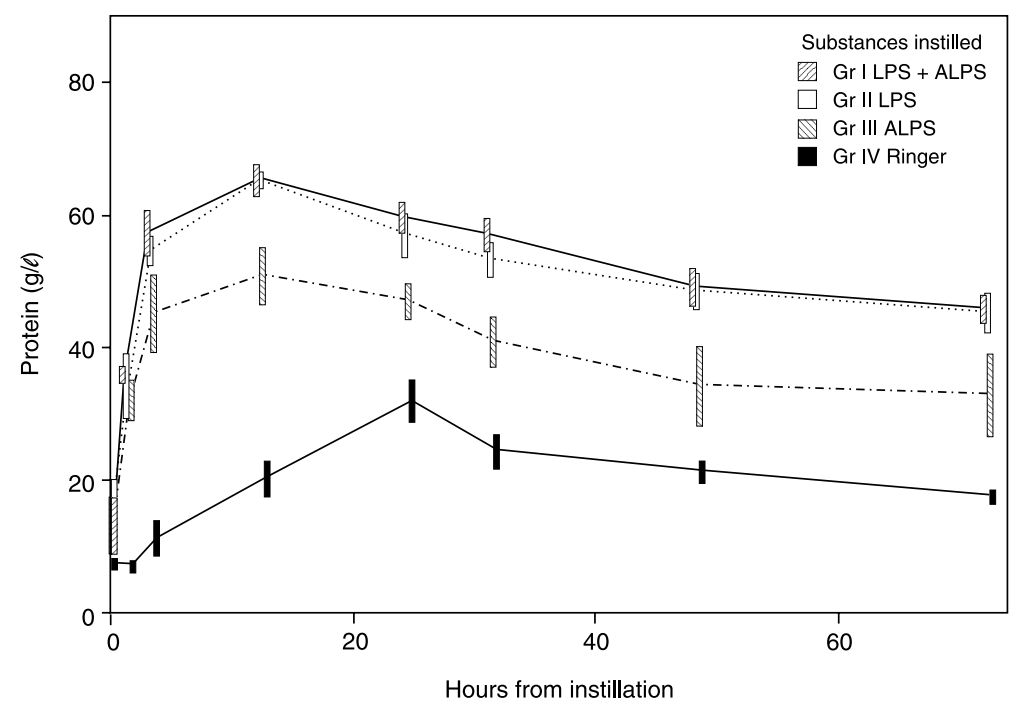

Fig. 1: Synovial fluid total protein.

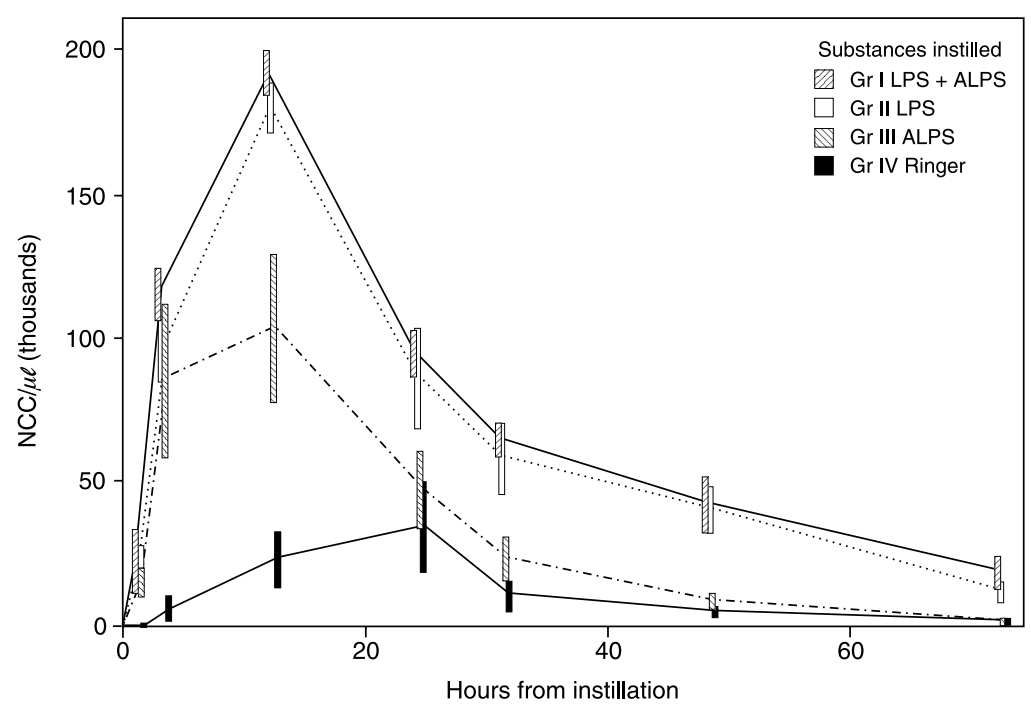

Fig. 2: Nucleated cell count (NCC).

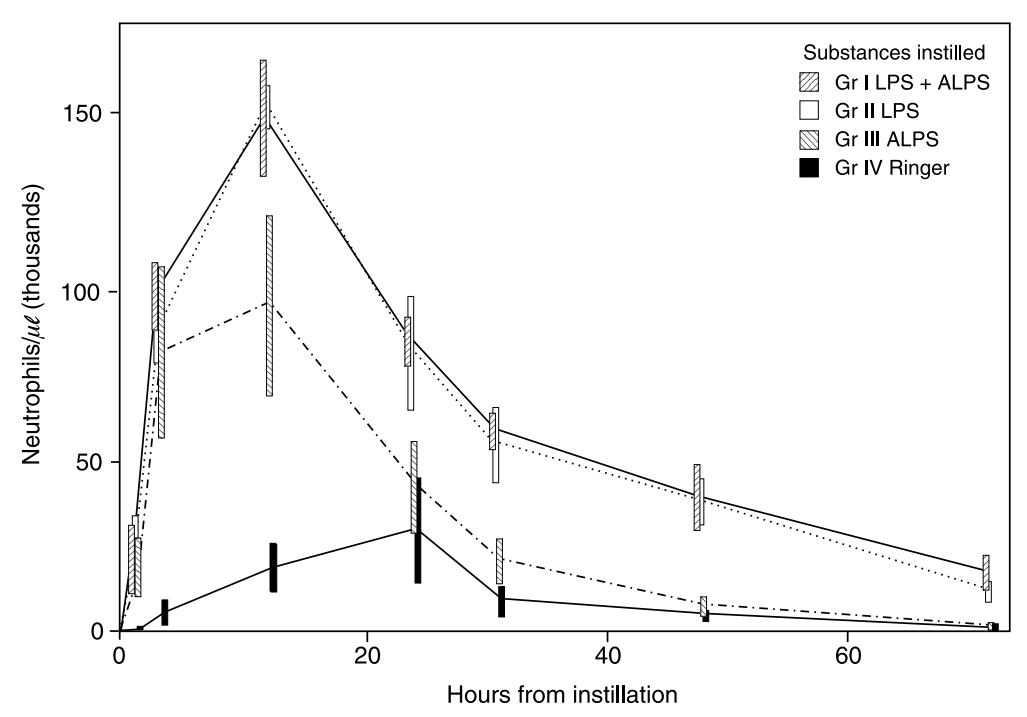

Fig. 3: Neutrophil count. 
acting primarily on the venules ${ }^{10}$. The protein values obtained in the synovial fluid samples are considered to be an indicator of the amount of inflammation that occurred in the joints. The synovial membrane, as well as blood vessels, could have been damaged during the arthrocentesis procedure. The inflammation caused by this procedure should be similar in all groups, as an identical number of needle punctures were performed in all horses. It is therefore the difference in inflammation between the groups that should be considered.

Using the total synovial protein values as an index of the inflammatory reaction in the joint, it can be deduced that antiLPS had no ameliorating effect on the inflammatory reaction caused by LPS and, in fact, caused a marked inflammatory reaction on its own. Repeated arthrocentesis and injection of Ringers lactate into the joint also caused an inflammatory reaction, but this was much milder than that caused by the other treatments. This concurs with the findings of Lloyd et al. ${ }^{14}$, who found a short-lived increase in synovial white blood cells, including neutrophils, after intra-articular injection of a sterile, polyionic physiological solution into catheterised equine antebrachiocarpal joints.

The anti-LPS injected into the joints had a protein concentration of $62.5 \mathrm{~g} / \mathrm{l}$. This would have affected the protein concentration of the synovial sample collected. As the synovial fluid volume of the intercarpal joint varied depending on the amount of effusion present in the joint, it is not possible to determine the contribution of the protein injected into the joint. However, considering the rapid increase in protein values in samples collected between 4 and $12 \mathrm{~h}$, it is unlikely that the contribution of the protein in the anti-LPS was significant. Furthermore, as no additional anti-LPS was administered, any increase in protein after $2 \mathrm{~h}$ cannot be attributed to this source.

The relatively high correlation between synovial leukocyte counts and protein concentration could result either from cellular debris due to cell breakdown in the synovial fluid, or the fact that that leukocytes were present when synovial inflammation was maximal and therefore the synovial membrane more permeable. The predominant leukocyte type present in the synovial fluid was the neutrophil, and this tends to support the latter alternative. It is widely accepted that endotoxins can exert profound effects on host mediation systems and 'turn on every defence' at the host's disposal ${ }^{21}$. The polysaccharide portion of the LPS is responsible for the activation of the alternate complement pathway ${ }^{2}$, activating complement in the absence of antibodies. Endotoxins are not particularly good antigens ${ }^{20}$, although they may activate the classic complement pathway by means of complexes formed by antigen and immunoglobulin IgG or $\operatorname{IgM}^{21}$. Complement $\left(C_{3 a}\right)$ is a chemotactic substance, attracting neutrophils, eosinophils and basophils, which form part of the $\mathrm{NCC}^{10}$. Other mediators of the inflammatory response initiated by LPS include products of arachidonic acid metabolism $^{19}$. Lipoxygenase enzymes metabolise arachidonic acid to a group of noncyclised eicosanoids, the leukotrienes. These compounds are of particular importance in leukocyte-mediated aspects of inflammation ${ }^{10}$ and probably help to account for the massive increase in NCC in Groups I and II, where LPS was injected into the joints. The increase in NCC in Group I indicated that anti-LPS appeared to have no ameliorating effects on the inflammation caused by the LPS. In fact, the anti-LPS appeared to have an inflammatory effect of its own, as evidenced by the results obtained in Group III. One could speculate that the protein present in the anti-LPS initiated an antibody response in the joint. The resultant antibody/antigen complexes could have, in turn, activated the classic complement pathway and its leukotactic effects. However, as there was no evidence to suggest prior sensitisation to the donor horse serum protein and the reaction was virtually immediate, this mechanism seems very unlikely. It is interesting to note that repeated arthrocentesis and joint distension with Ringers lactate (Group IV) was itself responsible for a relatively small, though significant, increase in NCC. The NCC also includes desquamated synovial cells. However, these made a very small contribution to the totals $(0.00017 \%$ at $8 \mathrm{~h})$.

Leitch $^{13}$ described the alteration of the predominating cell type from the mononuclear cell in normal equine synovial fluid to the segmented neutrophil, as the diagnostic hallmark of septic arthritis. The chemical synovitis caused by injection of foreign materials into joints in this trial resulted in a similar phenomenon. The findings of this trial also concur with the view of McIlwraith ${ }^{17}$, that any noxious substance injected into a joint can cause an equally dramatic neutrophil response. The differentiating feature between true septic arthritis and chemical synovitis is that, in chemical synovitis, the leukocytosis drops rapidly, while in septic arthritis it does not ${ }^{17}$.
As the principal function of neutrophils is phagocytosis of foreign matter, including bacteria and cellular debris ${ }^{24}$, it is not surprising that large numbers are found in naturally-occurring septic arthritis. In this trial, the high numbers of neutrophils were probably a direct response to the inflammatory reaction caused by injection of noxious substances into the joints, as no bacteria were noted in the neutrophils, and none were cultured from the synovial fluid.

The aim of this study was to evaluate the reported beneficial effect of anti-LPS in infectious arthritis ${ }^{27}$. The reported action of anti-LPS is to neutralise exogenous LPS and thereby abolish its deleterious effects on the joint ${ }^{8}$. In this trial, using an induced synovitis model according to Firth et al. ${ }^{7}$, anti-LPS appeared to have no neutralising effect on simultaneously injected LPS. It is acknowledged that anti-LPS has demonstrable antibacterial properties $^{9,28,29}$. Perhaps the reported beneficial effect of anti-LPS in clinical cases ${ }^{27}$ was due to the antibacterial rather than the anti-LPS activity of the product, or to other medication administered concurrently.

A possible inadequacy in the experimental design is that the level of naturally-occurring anti-LPS antibodies in the subjects was not ascertained. However, in the light of the findings of Hollingsworth \& Atkins ${ }^{11}$, namely that highly immunised rabbits retained their synovial reactivity to endotoxin, this inadequacy is unlikely to be important. The LPS may have had an immediate effect on synoviocytes. By injecting antiLPS after the LPS had already caused an inflammatory reaction, the interpretation of results could have been affected. Further studies should determine whether anti-LPS injected into the joint prior to the LPS would attenuate the inflammatory response. The amount of anti-LPS $(6.000 \mu \mathrm{g})$ used to neutralise the injected LPS (mean $470 \mu \mathrm{g}$ ) may have been insufficient. However, it is expected that at least some attenuation of the inflammatory response would have occurred. It is suggested that the beneficial effects reported when this product has been used in field cases may have been due to its known antibacterial effects.

The following conclusions can be drawn from the results of this trial: the induced synovitis model described by Firth et al. ${ }^{7}$ in ponies is valid in horses and was suitable for this trial. It appears that intraarticular injection of anti-LPS into the intercarpal joint of normal horses causes a transient synovitis. This synovitis was 
most marked at $8 \mathrm{~h}$ and decreased to near base-line levels at $72 \mathrm{~h}$. It is evident that anti-LPS had no effect in attenuating the clinico-pathological deviations of the LPS-induced synovitis model. The effects of introducing a sterile, balanced electrolyte solution into the intercarpal joint of normal horses, together with repeated arthrocentesis, indicate that this is not an innocuous procedure. This is in agreement with the findings of other authors ${ }^{5,14,33}$.

\section{ACKNOWLEDGEMENTS}

We thank Prof. J G Groeneveld for supervising and interpreting the statistical analyses, Ms Annaline van Heerden of the clinical pathology laboratory for timeconsuming and willing assistance in the processing of the synovial fluids, and Professors A Guthrie and J S van den Berg for their valuable input and editorial advice.

\section{REFERENCES}

1. Bertone A L, McIlwraith C W 1987 A review of current concepts in the therapy of infectious arthritis in the horse. Proceedings of the American Association of Equine Practitioners 1987: 323-339

2. Culbertson R, Osborn J R, Osborn B I 1980 The biological effects of bacterial endotoxin: a short review. Veterinary Sciences Communications 4: 3-14

3. Curtiss P H 1964 Changes produced in the synovial membrane and synovial fluid by disease. The Journal of Bone and Joint Surgery 46: 873-888

4. Duncan J R, Prasse K W 1986 Veterinary laboratory medicine (2nd edn). Ohio State University Press, Ames, Iowa

5. Dyke T M, Jeffcott L B 1988 Evaluation of synovial fluid parameters in natural and induced degenerative joint disease. Australian Equine Veterinary Association Newsletter 6: 38

6. Firth E C 1992 Specific orthopaedic infections In Auer J (ed.) Equine surgery. W B Saunders, Philadelphia, 936-939

7. Firth E C, Wensing T, Seuren F 1987 An induced synovitis disease model in ponies. Cornell Veterinarian 77: 107-118
8. Gaffin S L, Baker B, Du Preez J, Katzwinkel R, Fleming J, Brocke-Utne J G 1982 Prohylaxis and therapy with anti-endotoxin hyperimmune serum against gastroenteritis and endotoxaemia in horses. Proceedings of the American Association of Equine Practitioners 1982: 335-340

9. Gaffin S L, Wells M T 1987 A morphological study of the action of equine anti-lipopolysaccharide plasma on gram-negative bacteria. Journal of Medical Microbiology 24: 165-168

10. Higgins A J, Lees P 1984 The acute inflammatory process, arachidonic acid metabolism and the mode of action of anti-inflammatory drugs. Equine Veterinary Journal 16: 163-175

11. Hollingsworth J W, Atkins E 1965 Synovial inflammatory response to bacterial endotoxin. Yale Journal of Biology and Medicine 38: 241-256

12. Koterba A M, Drummond W H, Kosch P C 1990 Equine clinical neonatalogy. Lea and Febiger, London

13. Leitch M 1979 Diagnosis and treatment of septic arthritis in the horse. Journal of the American Veterinary Medical Association 175: 701-704

14. Lloyd K C K, Stover S M, Pascoe J R, Pool R, Kurpershoek C 1988 Effect of gentamycin sulfate and sodium bicarbonate on the synovium of clinically normal equine antebrachiocarpal joints. American Journal of Veterinary Research 49: 650-662

15. Madison J B, Somar M, Spencer P A 1991 Relations among synovial membrane histopathologic findings, synovial fluid cytological findings and bacterial culture results horses with suspected infectious arthritis: 64 cases (1979-1987). Journal of the American Veterinary Medical Association 198: 1655-1660

16. Matthews A G 1982 Serum protein electrophoresis in horses and ponies. Equine Veterinary Journal 14: 322-324

17. McIlwraith C W 1983 Comprehensive synovial fluid analysis - discussion. Proceedings of the American Association of Equine Practitioners 1983: 137-144

18. Miller R G 1981 Simultaneous statistical inference. Springer-Verlag, New York

19. Moore J N 1981 Biological reactions to endotoxin. The Compendium on Continuing Education for the Practising Veterinarian 3: 392-400

20. Moriarty K M 1984 Continuing education in immunology. 1: the structure and function of immunoglobulins. New Zealand Veterinary Journal 32: 61-64
21. Morrison D C 1978 The effects of bacterial endotoxins on host mediation systems. American Journal of Pathology 93: 527-617

22. Orsini J A 1984 Strategies for treatment of bone and joint infections in large animals. Journal of the American Veterinary Association 185: 1190-1193

23. Schneider R K, Bramlage L R, Mecklenburg L M, Moore R M, Gabel A A 1992 Open drainage and systemic antibiotics in the treatment of septic arthritis/tenosynivitis in horses. Equine Veterinary Journal 24: 433449

24. Smith H A, Jones T C, Hunt R D 1972 Veterinary pathology (4th edn). Lea and Febiger, London

25. Stashak T S 1987 Adams lameness in horses (4th edn). Lea \& Febiger, Philadelphia.

26. Steel R G D, Torrie J H 1980 Principles and procedures of statistics: a biometrical approach. McGraw-Hill, New York

27. Thomson M 1983 The use of equine antiendotoxin hyperimmune serum in the treatment of septic arthritis in foals. Journal of the South African Veterinary Association 54: 279-281

28. Wells M T, Gaffin S L 1987 Anti-Pseudomonas activity of anti-lipopolysaccharide hyperimmune equine plasma. Clinical Experimental Immunology 68: 86-98

29. Welsh M, Gaffin S L, Gregory M, Coovadia Y 1987 Properties of equine anti-lipopolysaccharide hyperimmune plasma: binding to lipopolysaccharide and bactericidal activity against gram-negative bacteria. Journal of Medical Microbiology 24: 187-196

30. Welsh N H, Rauch A J, Gaffin S L 1985 Topical immunotherapy for Pseudomonas keratitis in rabbits; use of anti-lipopolysaccharide plasma. British Journal of Ophthalmology 8: 328-832

31. Wessels B C, Gaffin S L 1986 Anti-endotoxin immunotherapy for canine parvovirus endotoxaemia. Journal of Small Animal Practice 27: 609-615

32. Wessels B C, Gaffin S L, Wells M T 1987 Circulating plasma endotoxin (lipopolysaccharide) concentrations in healthy and hemorrhagic enteric dogs: antiendotoxin immunotherapy in hemorrhagic enteric endotoxemia. Journal of the American Animal Hospital Association 23: 291-295

33. White K K, Hodgson D R, Hancock D, Parry B W, Cordell C 1989 Changes in equine carpal joint synovial fluid in response to the injection of two local anesthetic agents. Cornell Veterinarian 79: 25-38 